\section{Sequential blanking: A U-shaped function ${ }^{1}$}

J. L. ANDREASSI, M. S. MAYZNER, D. $B E Y D A$, and J. WAXMAN, New York University, Bronx, N.Y. 10453

The present study, employing a computer-based cathode-ray tube display system, involved four separate experiments directed to determining if sequential blanking consistently yields a U-shaped function with a variety of input configurations. $U$-shaped functions were found in all four experiments, and it was concluded that such functions are typical of sequential-blanking phenomena.

In a number of recent studies (Bell, Forster, Finnegan, Katz, LaSusa, \& Mayzner, 1969; Buchsbaum \& Mayzner, 1969; Mayzner, Tresselt, \& Helfer, $1967 \mathrm{a}, \mathrm{b})$ on sequential-blanking phenomena, U-shaped functions were found. The present study is concerned with confirming the shape of this function further by employing a variety of different input configurations, on-off times, and response measures. Four separate experiments were carried out with this objective in mind.

\section{SUBJECTS}

Forty students at the University Heights campus of New York University served as Ss, $10 \mathrm{Ss}$ in each of four different experiments.

\section{APPARATUS}

The stimuli were presented on two Fairchild CRT display consoles simultaneously, both slaved to a 340 master display, driven by a PDP-7 digital computer. A complete description of this hardware system and its associated computer programs (software) may be found in earlier papers (Mayzner, 1968; Mayzner, Tresselt, \& Helfer, 1967a).

\section{MATERIALS}

Experiments 1 and 2

The basic stimulus set consisted of 30 different display configurations, with each configuration consisting of a sequential letter display (display order, 31425), known from previous work (Mayzner, Tresselt, \& Helfer, 1967b) to produce strong sequential-blanking effects. A typical display configuration consisted of displaying to $S$ on the CRT console two lines of sequentially displayed letters, one line directly below the other, with one line containing three different letters and the other line containing the same three different letters, plus an additional two target letters, which were always identical, as follows:

$$
\begin{array}{llllll}
S & & & F & & P \\
S & K & F & K & P
\end{array}
$$

The target letters appeared in the top and bottom lines an equal number of times in a random sequence. The sequential display order of the letter array was, as indicated, 31425 , i.e., first, the letter $\mathrm{K}$ was displayed on the left; second, the $\mathrm{K}$ was displayed to the right; third, the top and bottom $S$ were displayed simultaneously; fourth, both Fs were displayed; and fifth, both Ps were displayed. Thirty such letter displays were constructed, 15 displays in which the target letters, displayed first and second and always identical, e.g., K, K, X, X, etc., appeared in the top line and another 15 identical displays, except the target letters appeared in the bottom line. These basic 30 displays were presented at four different on-off time combinations, i.e., $5 \mathrm{msec}$ on-5 msec off per input, $10 \mathrm{msec}$ on-10 msec off per input, 20 msec on- 20 msec off per input, and $50 \mathrm{msec}$ on-50 msec off per input, yielding a grand total of 120 testing trials per S, presented in a random order.

Individual letter size was $1 / 2 \mathrm{in}$. high and $3 / 8 \mathrm{in}$. wide, and the distance between the two lines of letters was $3 / 4$ in. for Experiment 1. Experiment 2 was identical in every respect to Experiment 1, except that the vertical distance between the two lines of letters was $23 / 4$ in. $S$ was positioned 24 in. from the CRT console. Display luminance for an individual letter was approximately $1 \mathrm{~mL}$, as measured with a Macbeth illuminometer under steady-state conditions. Fixation was provided by placing a black cardboard cover over the CRT console, with a cutout 6 in. wide by 3 in. high through which the two lines of three and five letters could be viewed in
Experiments 1 and 2. A fixation point was employed and was placed midway between the middle letter of the two lines of letters. Experiments 3 and 4

In Experiment 3, the stimulus material consisted of a line of five Xs displayed sequentially in the order 31425 . Nine different on-off time combinations were examined with 10 trials per combination, for a grand total of 90 trials, with the different timing combinations presented in a random order. These timing combinations (in milliseconds) were: 1 on-1 off, 5 on -5 off, 10 on- 10 off, 15 on-15 off, 20 on-20 off, 25 on- 25 off, 30 on -30 off, 40 on-40 off, and 50 on-50 off.

In Experiment 4, the single $X$ of Experiment 3 was replaced with a column of five Xs, and all other conditions were identical except for slight changes in the nine timing combinations (in milliseconds) as follows: 1 on- 1 off, 5 on-5 off, 10 on-10 off, 15 on-15 off, 20 on-20 off, 30 on-30 off, 50 on-50 off, 75 on-75 off, 100 on-100 off. Letter size, display luminance, and distance of $S$ from CRT were identical in all four experiments.

\section{PROCEDURE}

Experiments 1 and 2

The $\mathrm{S}$ was instructed that he would be shown a series of letter displays. Each display would consist of lines of letters, one above the other: one line containing three different letters and two blank spaces and the other line containing the same three different letters plus two target letters, which would always be identical, corresponding to the blank spaces of the other line. He was told his task was to write down, on the prepared answer form before him, the target letter for each display shown him. Illumination for this task was provided by a tensor lamp placed about $3 \mathrm{ft}$ behind each S's writing desk. Two Ss were tested simultaneously, one at each of the two Fairchild CRT display consoles, with a black cardboard shield separating the Ss. Each $S$ was given sufficient practice trials to thoroughly familiarize him with the task. Before each display was presented, S was told "fixate" and then "ready," and the display occurred about $1 \mathrm{sec}$ after this ready signal.

Experiments 3 and 4

The $S$ was instructed that he would see a line of Xs (Experiment 3) or columns of Xs

Table 1

Per Cent Correct Detections for Experiments 1 and 2 and Mean Number of Xs and Columns of Xs Reported for Experiments 3 and 4

\begin{tabular}{|c|c|c|c|c|c|c|c|c|c|c|c|}
\hline \multirow{2}{*}{$\begin{array}{l}\text { Experi- } \\
\text { ment }\end{array}$} & \multicolumn{11}{|c|}{ On-Off Time Combinations (in Msec) } \\
\hline & $1-1$ & $5-5$ & $10-10$ & $15-15$ & $20-20$ & $25-25$ & $30-30$ & $40-40$ & $50-50$ & $75-75$ & $100-100$ \\
\hline 1 & & $82 \%$ & $70 \%$ & & $71 \%$ & & & & $90 \%$ & & \\
\hline 2 & & $28 \%$ & $19 \%$ & & $26 \%$ & & & & $53 \%$ & & \\
\hline 3 & 5.06 & 4.92 & 4.60 & 3.96 & 4.04 & 4.06 & 4.24 & 4.32 & 4.47 & & \\
\hline 4 & 5.57 & 5.30 & 4.67 & 3.81 & 3.38 & & 3.66 & & 3.68 & 4.06 & 4.30 \\
\hline
\end{tabular}


(Experiment 4), five $X s$ in a column, and that he was to indicate how many Xs were present (Experiment 3) or how many columns of Xs (Experiment 4) were present. All other relevant procedural variables were identical in all four experiments.

\section{RESULTS AND DISCUSSION}

The major results of the study are presented in Table 1, which gives the per cent correct detections for Experiments 1 and 2 and the mean number of $X s$ and columns of Xs reported for Experiments 3 and 4 , for all the various timing combinations examined. The Friedman two-way analysis of variance by ranks test (Siegel, 1956) was applied to the scores shown in Table 1 for each of the four experiments separately, and the results were as follows: Experiment 1$\chi_{\mathrm{r}}^{2}=16.20, \mathrm{df}=3, \mathrm{p}<.005$; Experiment $2-\chi_{\mathbf{r}}^{2}=19.92, \mathrm{df}=3$, $p<.001 ; \quad$ Experiment $3-\chi_{\mathrm{I}}^{2}=30.96$, df $=8, \quad \mathrm{p}<.001 ; \quad$ Experiment $4-$ $\chi_{\mathrm{r}}^{2}=59.88$, df $=8, \mathrm{p}<.001$.

Examination of Table 1 and Figs. 1 and 2 reveals clearly that a U-shaped sequential-blanking function was obtained in all four experiments. Experiments 1 and 2 were designed to employ a very precise "objective-indicator methodology," in that $S$ had before him simultaneously a display line that contained target letters and a display line that did not contain any target letters, and in both Experiments 1 and 2, U-shaped sequential-blanking functions were obtained. Further, it is clear from comparing Experiment 1 with Experiment 2 that while increasing the vertical distance between these two lines decreases overall detection performance, it does little to affect the U-shaped nature of the function. It might also be noted that in Experiments 1 and 2, by using two identical target letters, we have made the S's detection task particularly easy, provided that the lines are relatively close together, and still a $\mathrm{U}$-shaped function is obtained.

In Experiments 3 and 4, we again find clear evidence of a U-shaped sequential-blanking function, using a different type of indicator methodology. In fact, for the very fast input rates, i.e., $1 \mathrm{msec}$ on $-1 \mathrm{msec}$ off or $5 \mathrm{msec}$ on-5 msec off, we find a tendency for $\mathrm{S}$ to report more $\mathrm{Xs}$ or columns of $\mathrm{Xs}$ than were actually displayed; the very timing conditions that a monotonic decreasing function would predict as yielding the poorest detection performance. The fastest input rates

Fig. 2. Mean number of stimuli reported as a function of on-off time, Experiments 3 and 4.

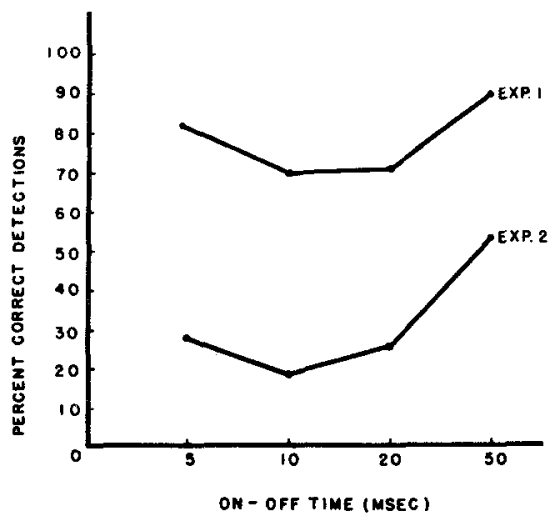

with a five-input array (Mayzner, Tresselt, \& Helfer, 1967b). Further, our results are in agreement with the studies of Dember \& Purcell (1967), Kahneman (1967, 1968), Schiller \& Chorover (1966), and Weisstein (1968), which have reported U-shaped functions. We conclude, therefore, that U-shaped sequential-blanking functions represent a fundamental characteristic of visual-information-processing mechanisms with sequential inputs.

Fig. 1. Per cent correct detections as a function of stimulus on-off times, Experiments 1 and 2.

produce higher detection scores than do the slowest rates; we would attribute this to the fact that, at the fastest rates, Ss report, introspectively, that all $\mathrm{Xs}$ or columns of $X s$ were present simultaneously, while at the slowest rates, the Xs or columns of Xs were clearly sequential, and with this sequentiality, "counting" of the exact number of elements present appeared much more difficult. It is interesting to note that a more pronounced U-shaped function resulted in Experiment 4, as compared to Experiment 3. This may indicate that a stronger blanking effect occurred with five columns of five Xs as compared with a single row of five Xs.

In general, the results of Experiments $1-4$ are in line with previous findings showing sequential-blanking effects to be maximum at about an input rate of $20 \mathrm{msec}$ on- $20 \mathrm{msec}$ off per input,

\section{REFERENCES}

BELL, A., FORSTER, R. G., FINNEGAN, F. J., KATZ, M., LaSUSA, J. I., \& MAYZNER, M. S. Sequential blanking and visual form perception. Psychonomic Science, 1969, 15, 103-104.

BUCHSBAUM, w. H., \& MAYZNER, M. S. The effects of line length on sequential blanking. Psychonomic Science, 1969, 15, 111-112.

DEMBER, W. N., \& PURCELL, D. G. Recovery of masked visual targets by inhibition of the masking stimulus. Science, 1967, 157, $1335-1336$. of apparent motion and metacontrast. Perception \& Psychophysics, 1967, 3, 577-584.

MAYZNER, M. S. The research potential of a computer-based cathode-ray tube display system. Behavior Research Methods \& Instrumentation, 1968, 1, 41-43.

MAYZNER, M. S., TRESSELT, M. E., \& HELFER, M. S. A research strategy for studying certain effects of very fast sequential input rates on perception. Psychonomic Monograph Supplements, 1967a, 2(5, Whole No. 21), 73-81.

MAYZNER, M. S., TRESSELT, M. E., \& HELFER, M. S. A provisional model of visual information processing with sequential inputs.
KAHNEMAN, D. An onset-onset law for one case

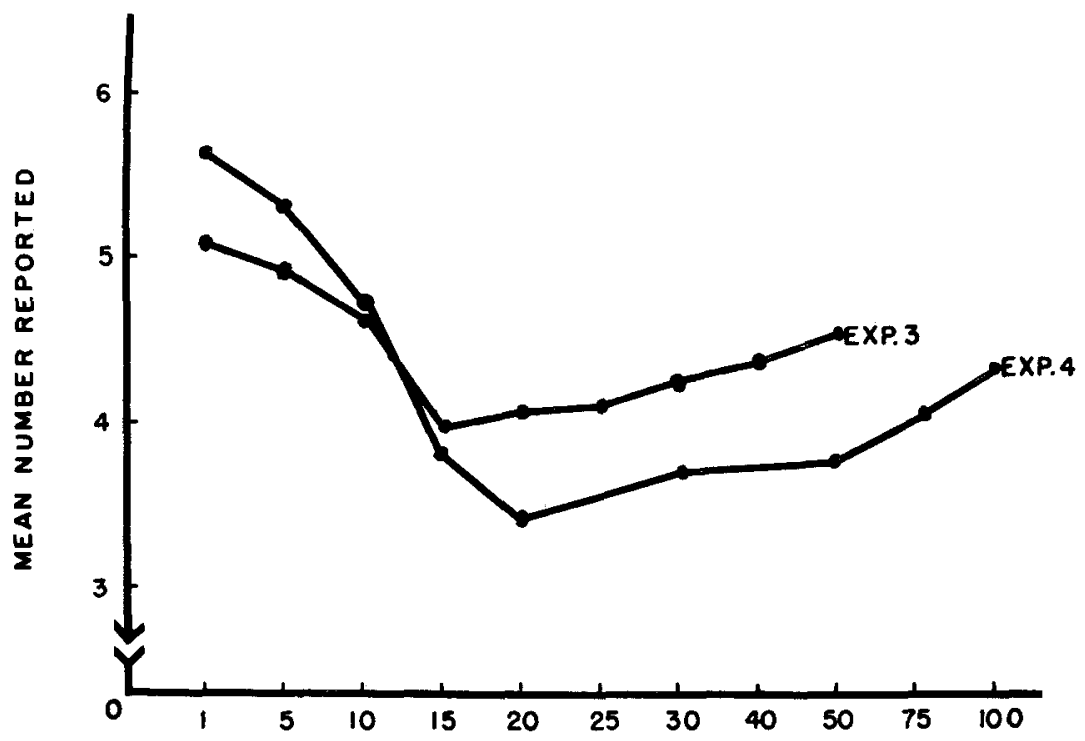

ON-OFF TIME (MSEC) 
Psychonomic Monograph Supplements, 1967b, 2(7, Whole No. 23), 91-108.

SCHILLER, P. N., \& CHOROVER, S. L. Metacontrast: Its relation to evoked potentials. Science, 1966, 153, 1398-1401.

SIEGEL, S. Nonparametric statistics for the behavioral sciences. New York: McGraw-Hill, 1956.

WEISSTEIN, N. A Rashevsky-Landahl neural net: Simulation of metacontrast. Psychological Review, 1968, 75, 494-521. NOTE

1. This research was supported by the Physiological Psychology Program, Office of Naval Research, under ONR Contract No. N00014-67-A-0467-0009 and ONR Contract Authority No. NR $140-252$ to the first two authors.

\section{Children's discrimination learning as a function of intertrial interval duration}

\author{
WILLIAM L. CROLL, Institute of Child \\ Behavior and Development, University of \\ Iowa, Iowa City, Iowa 52240
}

Preschool children were trained on a successive discrimination in which four stimulus-response associations were learned concurrently, with different groups of $\mathrm{Ss}$ receiving ITI durations of $1,6,11$, and $16 \mathrm{sec}$. Learning rate was slower with a 1-sec duration than with a 6-, 11-, or 16-sec duration; but there was no difference in learning rate among the latter three durations. The results are compatible with the hypothesis that in such a task children do not benefit from opportunities to rehearse beyond several seconds because they do not retain the stimulus information needed for rehearsal.

The variables affecting children's discrimination learning have been extensively studied, but one potentially important variable, intertrial interval (ITI) duration, has been ignored. Several studies of adult concept utilization have found learning rate to depend upon ITI duration, suggesting that a similar effect might be obtained in children's discrimination learning (Bourne \& Bunderson, 1963; Bourne, Guy, Dodd, \& Justesen, 1965). Further suggestion of an ITI effect in children's discrimination learning is found in the effect of ITI duration on the accuracy of children's predictive behavior (Bogartz, 1967).

The present experiment investigated the effects of ITI duration in children's discrimination learning. Preschool children were trained on a successive discrimination in which four stimulus-response associations were learned concurrently, with different Ss receiving ITI durations of $1,6,11$, and $16 \mathrm{sec}$.

\section{METHOD}

The Ss were 68 children from the Preschool Laboratories of the Institute of Child Behavior and Development at the University of Iowa. They ranged in age from 55 to 69 months, with a mean of 63.4 months.

A translucent glass screen, 5 in. high and 12 in. wide, was mounted 33 in. above the floor on a wall of the experimental room. Stimuli were projected onto this screen by a slide projector recessed behind it. These stimuli were geometric forms, including a star, a rectangle, a diamond, and a circle. A horizontal array of four response buttons was centered 4 in. below the screen, with 2 in. between adjacent buttons. All stimulus events and time intervals were automatically controlled.

Each $\mathrm{S}$ was brought individually to the experimental room, shown a display of toys, and told that he could win one by playing a game. He was then seated before the screen and told: that pictures would appear on the screen, that each picture "belongs to" a button, and that he should press the button that he thought "belongs to" the picture being presented.

Each trial began with presentation of one of the four stimuli. When $S$ depressed any of the four buttons, the stimulus was immediately terminated, and $E$ immediately said "Yes" (if the response was correct) or "No" (if the response was incorrect). Stimulus offset initiated the ITI, which continued until onset of the stimulus for the next trial and during which the stimulus screen was blank. The Ss were assigned randomly to one of four ITI groups: 1, 6, 11, and $16 \mathrm{sec}$. Ss in a given ITI group received an ITI of that duration on each trial. The order in which the Ss were trained was balanced so that the number of $S s$ trained in one group never exceeded the number in any other group by more than two.

Each $S$ received 96 trials, 24 with each of the four stimuli. The order of stimulus presentations was random except that each of the four stimuli occurred exactly four times in each block of 16 trials, and no stimulus ever followed itself. The assignment of stimuli to response buttons was randomized across Ss.

\section{RESULTS}

The relative frequency of a correct response for each ITI group is given as a function of trial blocks in Table 1. An analysis of variance was performed on these scores, with ITI and trial blocks as factors. An .01 level of significance was employed for all tests. The interaction of ITI and trial blocks was significant $[F(15,320)=3.49]$ as was the effect of trial blocks $[\mathrm{F}(5,320)=35.30]$. The ITI effect was not significant $[F(3,64)=2.58]$. Table 1 suggests that the obtained interaction of ITI and trial blocks might have resulted from Groups 6, 11, and 16 increasing at a faster rate than Group 1. This was supported by two further analyses. The first compared the performance of Groups 6,11, and 16, deleting the data of Group 1. In this analysis, the ITI by Trial Blocks interaction was not significant $[F(10,240)=0.76]$, indicating that learning rate was the same for these groups. The trial blocks effect was again significant $[F(5,240)=30.39]$, and the ITI effect was again nonsignificant $[F(2,48)=0.13]$. The second analysis compared the data of Group 1 with the combined data of Groups 6,11 , and 16 . The ITI by Trial Blocks interaction was significant $[F(5,330)=6.39]$, suggesting that the learning rate of Group 1 was lower than that of the remaining groups. The trial blocks and ITI effects were both significant $[F(5,330)=27.08$ and $F(1,66)=7.66$, respectively].

\section{DISCUSSION}

The observed inferiority of performance under the 1-sec ITI duration is consistent with the results from adult concept-utilization experiments, but the failure to find a difference among the 6-, $11 \cdot$, and 16-sec ITI durations is

Table 1

Relative Frequency of a Correct Response as a Function of ITI Duration and Trial Blocks

\begin{tabular}{|c|c|c|c|c|}
\hline \multirow{2}{*}{$\begin{array}{l}\text { Trial } \\
\text { Block }\end{array}$} & \multicolumn{4}{|c|}{ ITI Duration (Sec) } \\
\hline & 1 & 6 & 11 & 16 \\
\hline 1 & .353 & .371 & .335 & .386 \\
\hline 2 & .379 & .515 & .463 & .533 \\
\hline 3 & .419 & .548 & .500 & .625 \\
\hline 4 & .401 & .629 & .563 & .662 \\
\hline 5 & .401 & .699 & .706 & .688 \\
\hline 6 & .353 & .765 & .706 & .662 \\
\hline
\end{tabular}

